\title{
Archaeometric analysis of ceramic production and exchange from the Neolithic to the Gallo-Roman period in Brittany, France
}

\author{
Benjamin Gehres*
}

This short article reports research on the development of ceramic production and exchange between the mainland and islands of Brittany from the Neolithic to the GalloRoman period. Archaeometric analysis of ceramics is used to explore the development of communication networks: the movement of people and of products between the islands and the mainland. Did these islands produce their own pottery or were they dependent on mainland production? By determining whether pottery was locally produced or imported, it is possible to identify the changing degrees of connection with, or isolation from, wider networks.

The geological framework for this research is the Armorican peninsula (Figure 1), a crystalline massif composed of magmatic and metamorphic rocks. The formation of clay sources on the Armorican Massif differs from sedimentary areas, such as the Parisian Basin, as the clays have not been transported across long distances and redeposited. As a result, deposits are more localised, more numerous and smaller than in sedimentary basins, and, in most cases, the geological markers in these clays come from the local parent rock or from nearby formations. The specific geological properties of these clays were exploited to produce different types of pottery.

Several analytical methods have been employed to examine 368 sherds of pottery from 25 sites. Macroscopic observations were made in order to document surface treatments, as well as microscopic examination of ceramic thin sections for the identification of the mineralogical composition of the clay, and to determine its geological and geographic origins. These techniques have been complemented with chemical analyses: SEM-EDS, XR-D and P-XRF.

Finally, a new methodological approach has been used to provenance the clays: LA-ICPMS analysis. This method is based on chemical comparisons of the mineral inclusions in the ceramic pastes with the same mineral types in the parent rocks (Gehres \& Querré in press). It can determine more precisely the origins of clays, especially when the pastes do not offer characteristic elements that allow them to be distinguished from other productions. This approach has been developed for several mineral types so far, including biotite,

\footnotetext{
* CReAAH (Centre de Recherche en Archéologie, Archéosciences, Histoire), UMR 6566, University of Rennes 2, Rue du Thabor, 35000 Rennes, France (Email: benjamin.gehres@gmail.com)
} 


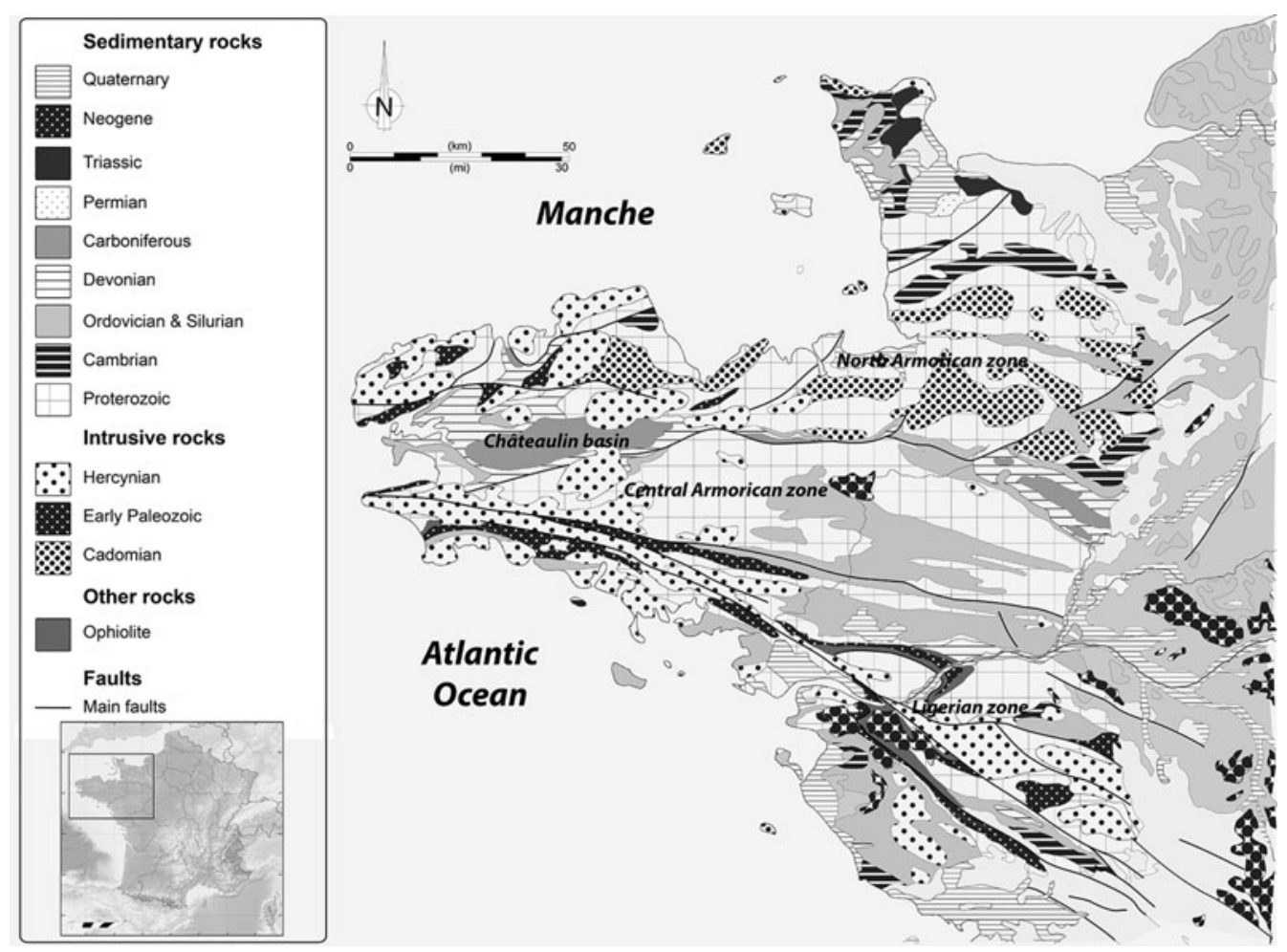

Figure 1. Geological map of the Armorican Massif (France)

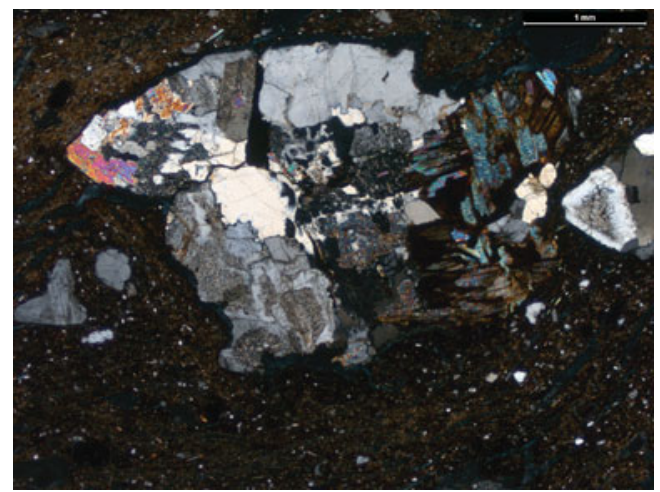

Figure 2. Micrograph of a granitic paste ceramic with fragment of granite.

amphibole and opaque minerals. We have also extended this method to the identification of biominerals, with the analysis of shell inclusions, in order to determine whether they are fossil material or were deliberately added by potters.

The LA-ICP-MS analysis permits the observation of diverse aspects of ceramic production and exchange. For example, most of the biotite in pottery discovered in the Glenan archipelago (Finistère) and the Ile aux Moutons (Finistère) (Figure 2) corresponds (C) Antiquity Publications Ltd, 2017 


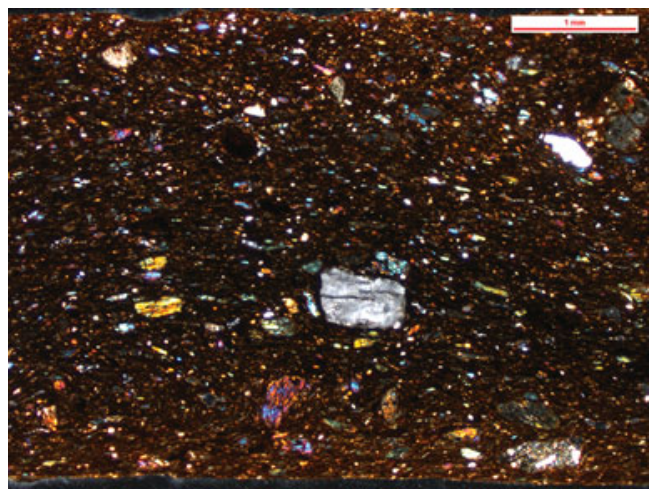

Figure 3. Micrograph of a gabbroic paste ceramic. The coloured inclusions are grains of amphibole.

to the biotite signatures from mainland granites. Contrary to the results of the petrographic observations, the LA-ICP-MS analysis therefore indicates that there was no ceramic production in the Glenan archipelago between the Late Neolithic and the Late Iron Age. Similarly, analyses of grains of amphibole in ceramic pastes of the Late Iron Age confirm the use of weathered products from two different gabbroic massifs (Figure 3): Saint-Jeandu-Doigt (Finistère) and Trégomar (Côtes d'Armor). It has been possible to determine the origin of pottery made with gabbroic clays found in remote locations, several hundred kilometres away, such as Mez-Notariou (the island of Ouessant, Finistère) or the Batterie Basse (Urville-Nacqueville, Manche).

The long chronological scope of this study allows us to document the evolution of ceramic characteristics and the changing locations of clay supply and pottery production. In particular, we have been able to highlight periods with significant change in the size of non-plastic inclusions: one during the Bronze Age, with an increase in grain size, and a second, in the Late Iron Age, with a sharp decrease associated with the adoption of the potter's wheel.

Over time, islanders imported more of their pottery from the mainland, with exchange between the islands decreasing. During the Neolithic period, household-type production made use of mainly local materials; by the Bronze Age, the importation of pottery from the mainland grew in importance, implying the existence of commercial exchange alongside local household industry production. During the Iron Age, imports from the mainland became more important than local pottery because of new types of production: the individual workshop industry or nucleated workshop. In fact, during this period, three workshop areas have been identified by the petrographic analyses of ceramics. Finally, during the Roman period, there is further reduction in the production of local pottery on the islands, in favour of imports from the mainland, where production was now organised as nucleated workshops.

The results of this research provide new evidence about the prehistoric occupation of the islands of Brittany. The petrographic and chemical analyses of ceramics reveal the changing organisation of pottery production and exchange. The pottery used on these islands does 
not indicate insular particularism; instead, there were close relations between the islands and the mainland, and both practised similar pottery-production techniques.

\section{Reference}

Gehres, B. \& G. Querré. In press. La signature chimique des inclusions minérales comme traceur de l'origine des céramiques: l'apport des analyses par LA-ICP-MS, actes du workshop 'Matières à penser', Mai 2015, Namur (Belgium). Bulletin de la Société Préhistorique Française. 